\title{
Upper brachial plexus injury in adults: comparative effectiveness of different repair techniques
}

\author{
Zarina S. Ali, MD, ${ }^{1}$ Gregory G. Heuer, MD, PhD, ${ }^{1,2}$ Ryan W. F. Faught, BS, ${ }^{1}$ Shriya H. Kaneriya, BA, ${ }^{1}$ \\ Umar A. Sheikh, BA, ${ }^{1}$ Idrees S. Syed, BA, ${ }^{1}$ Sherman C. Stein, MD, ${ }^{1}$ and Eric L. Zager, MD ${ }^{1}$ \\ 1Department of Neurosurgery, University of Pennsylvania; and 'Division of Neurosurgery, The Children's Hospital of Philadelphia, \\ Philadelphia, Pennsylvania
}

\begin{abstract}
OBJECT Adult upper trunk brachial plexus injuries result in significant disability. Several surgical treatment strategies exist, including nerve grafting, nerve transfers, and a combination of both approaches. However, no existing data clearly indicate the most successful strategy for restoring elbow flexion and shoulder abduction in these patients. The authors reviewed the literature to compare outcomes of the three surgical repair techniques listed above to determine the optimal approach to traumatic injury to the upper brachial plexus in adults.
\end{abstract}

METHODS Both PubMed and EMBASE databases were searched for English-language articles containing the MeSH topic "brachial plexus" in conjunction with the word "injury" or "trauma" in the title and "surgery" or "repair" as a MeSH subheading or in the title, excluding pediatric articles and those articles limited to avulsions. The search was also limited to articles published after 1990 and containing at least 10 operated cases involving upper brachial plexus injuries. The search was supplemented with articles obtained through the "Related Articles" feature on PubMed and the bibliographies of selected publications. From the articles was collected information on the operation performed, number of operated cases, mean subject ages, sex distribution, interval between injury and surgery, source of nerve transfers, mean duration of follow-up, year of publication, and percentage of operative success in terms of elbow flexion and shoulder abduction of the injured limb. The recovery of elbow flexion and shoulder abduction was separately analyzed. A subanalysis was also performed to assess the recovery of elbow flexion following various neurotization techniques.

RESULTS As regards the restoration of elbow flexion, nerve grafting led to significantly better outcomes than either nerve transfer or the combined techniques $(F=4.71, p=0.0097)$. However, separating the Oberlin procedure from other neurotization techniques revealed that the former was significantly more successful $(F=82.82, p<0.001)$. Moreover, in comparing the Oberlin procedure to nerve grafting or combined procedures, again the former was significantly more successful than either of the latter two approaches $(F=53.14 ; p<0.001)$. In the restoration of shoulder abduction, nerve transfer was significantly more successful than the combined procedure $(p=0.046)$, which in turn was significantly better than nerve grafting procedures $(F=5.53, p=0.0044)$.

CONCLUSIONS According to data in this study, in upper trunk brachial plexus injuries in adults, the Oberlin procedure and nerve transfers are the more successful approaches to restore elbow flexion and shoulder abduction, respectively, compared with nerve grafting or combined techniques. A prospective, randomized controlled trial would be necessary to fully elucidate differences in outcome among the various surgical approaches.

http://thejns.org/doi/abs/10.3171/2014.9.JNS132823

KEY WORDS brachial plexus injury; upper trunk injury; nerve graft; nerve transfer; Oberlin procedure; peripheral nerve

$\mathrm{U}$ PPER trunk brachial plexus injuries involving the C5-6 roots result in significant disability due to a loss of shoulder abduction, external rotation, elbow flexion, and forearm supination. Involvement of the C-7 spinal root may lead to deficits involving additional movements, including finger, wrist, and elbow extension. The severity of these injuries varies from a neurapraxic injury, which typically resolves spontaneously, to a complete avulsion injury, which has no potential for spontaneous recovery. In adults, the restoration of elbow flexion is the highest priority, followed by shoulder abduction and external rotation., ${ }^{3,68}$

Historically, repair strategies have consisted of brachial plexus exploration and reconstruction with nerve graft-

ABBREVIATION MRC $=$ Medical Research Council.

SUBMITTED November 10, 2013. ACCEPTED September 2, 2014.

INCLUDE WHEN CITING Published online October 31, 2014; DOI: 10.3171/2014.9.JNS132823.

DISCLOSURE The authors report no conflict of interest concerning the materials or methods used in this study or the findings specified in this paper. 
ing. More recently, distal nerve transfers, which have traditionally been reserved for nerve root avulsion injuries, have been popularized for the treatment of postganglionic nerve injuries. This approach sacrifices a functional donor nerve fascicle in an attempt to reinnervate a recipient denervated target muscle. In fact, many surgeons now choose to forgo brachial plexus exploration and rely solely on distal nerve transfers. ${ }^{1,11,38,62}$ However, no prospective, randomized controlled trials have compared these surgical repair strategies. We reviewed the literature to evaluate the outcomes of three surgical approaches for the repair of postganglionic upper trunk brachial plexus injuries in adults, including nerve grafting, nerve transfer, and a combination of both techniques.

\section{Methods}

\section{Literature Review}

In January 2013, we searched the PubMed and EMBASE databases for articles containing the MeSH topic "brachial plexus" in conjunction with the word "injury" or "trauma" in the title and "surgery" or "repair" as a $\mathrm{MeSH}$ subheading or in the title, excluding pediatric articles and those articles limited to avulsions. We limited our search to English-language articles published after 1990 and articles containing at least 10 operated cases involving upper (or upper plus middle) brachial plexus injuries. The search was supplemented with articles obtained through the "Related Articles" feature of PubMed and the bibliographies of selected publications. All abstracts were reviewed, and those that were clearly unrelated to the purpose of our study were discarded. At least two authors reviewed each remaining article for relevance and data. If an article reported more than one surgical approach, we attempted to separate outcomes in each group. If this was not possible, the article was eliminated from further review unless at least $60 \%$ of the cases utilized a single approach. From the articles, we abstracted information on the operation performed, number of operated cases, mean subject ages, sex distribution, interval between injury and surgery, source of nerve transfers, mean duration of follow-up, year of publication, and percentage of operative success in terms of elbow flexion and shoulder abduction of the injured limb. We also recorded the mean length of nerve grafts when available. We defined success as a British Medical Research Council (MRC) score of at least 3. ${ }^{42}$

\section{Analysis}

We compared three operations, including nerve repair (grafting), nerve transfer, and combinations of both techniques, to determine the optimal approach in an adult presenting with traumatic injury to the upper brachial plexus. The recoveries of both shoulder abduction and elbow flexion were assessed separately. We also performed a subanalysis in which we compared recovery of elbow flexion after each of the three nerve transfer techniques: partial ulnar nerve transfer (Oberlin procedure), intercostal transfer, and other procedures. Variables were abstracted from individual publications, tested to exclude heterogeneity, ${ }^{33}$ and pooled. We pooled data on success rates and demographics meta-analytically by using an in- verse variance-weighted random-effects model. ${ }^{17}$ Rates of different approaches were compared using 1-way ANOVA, with Bonferroni correction for ad hoc comparisons. The effects of patient age, injury-to-surgery period, and other covariates (predictive factors) were evaluated using meta-regression. Meta-analytical pooling, meta-regressions, and statistical comparisons of outcomes involved the use of Stata version 12 (StataCorp LP). A p value < 0.05 was considered significant.

\section{Results}

\section{Literature Review}

Our search yielded 2330 publications, many of which lacked utilizable data (Fig. 1). We used 71 case series in our analysis, including 5 series reporting more than one surgical approach (Table 1). 2,4-10,12-16,18-20,22-27,29-32,35-37,3941,43,44,46,48-61,63-67,69-82 However, none was a controlled trial, and all must be considered Class IV evidence. Fifteen series (747 cases) reported the results of nerve grafting. In the nerve transfer group, there were 54 reports with a total of 2440 cases. For combined procedures, the totals were 8 and 587, respectively. A breakdown of the nerve transfer group yielded 300 cases with partial ulnar transfer, 1052 with intercostal transfer, and 1088 undergoing other transfer procedures.

\section{Demographics, Surgical Timing, and Follow-Up}

Findings on patient demographics, surgical timing, and follow-up are summarized according to treatment
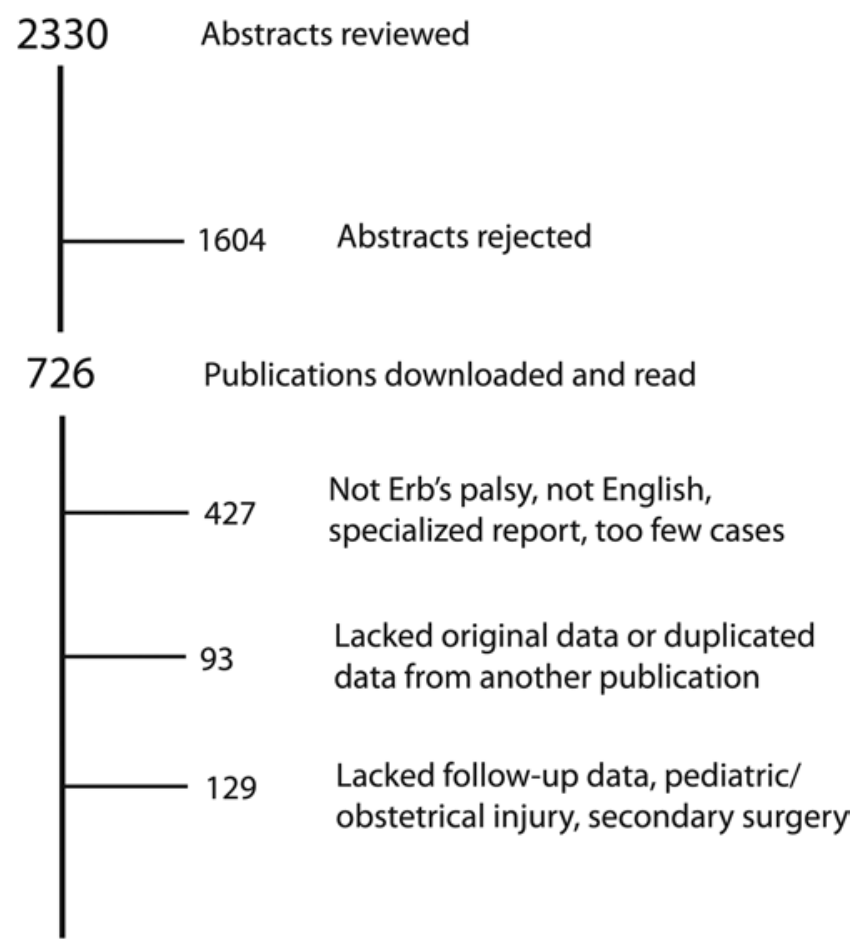

\section{Articles used for this report}

FIG. 1. Summary of the structured literature review performed, showing numbers of abstracts reviewed, articles read and/or used in our analysis, and reasons for rejections. 
TABLE 1. Case series used in an analysis of surgical procedures for upper brachial plexus injuries in adults

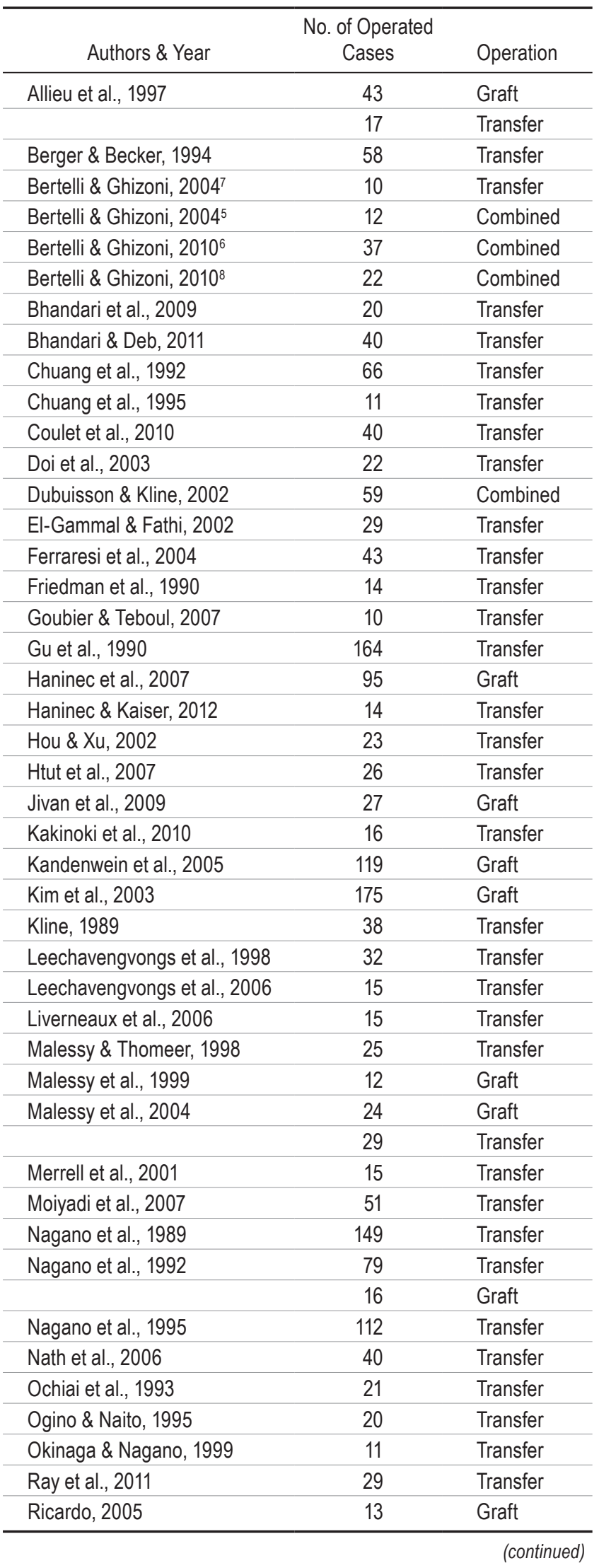

TABLE 1. Case series used in an analysis of surgical procedures for upper brachial plexus injuries in adults (continued)

\begin{tabular}{|c|c|c|}
\hline \multicolumn{3}{|c|}{ No. of Operated } \\
\hline Authors \& Year & Cases & Operation \\
\hline Richardson, 1997 & 10 & Transfer \\
\hline Ruch et al., 1995 & 17 & Transfer \\
\hline Samadian et al., 2009 & 17 & Graft \\
\hline Samardzic et al., 1992 & 22 & Transfer \\
\hline \multirow[t]{2}{*}{ Samardzić et al., 2002} & 25 & Transfer \\
\hline & 91 & Combined \\
\hline Samii et al., 1997 & 54 & Graft \\
\hline Samii et al., 2003 & 44 & Combined \\
\hline Siqueira \& Martin, 2009 & 10 & Transfer \\
\hline Socolovsky et al., 2011 & 34 & Graft \\
\hline \multirow[t]{2}{*}{ Socolovsky et al., 2012} & 18 & Transfer \\
\hline & 17 & Graft \\
\hline \multirow[t]{2}{*}{ Songcharoen, 1995} & 222 & Transfer \\
\hline & 23 & Graft \\
\hline Songcharoen et al., 1996 & 216 & Transfer \\
\hline Sulaiman et al., 2009 & 131 & Transfer \\
\hline Sungpet et al., $2000^{70}$ & 10 & Transfer \\
\hline Sungpet et al., $2000^{71}$ & 36 & Transfer \\
\hline Suzuki et al., 2007 & 12 & Transfer \\
\hline Teboul et al., 2004 & 34 & Transfer \\
\hline Terzis et al., 1999 & 204 & Combined \\
\hline Terzis \& Kostas, 2006 & 118 & Combined \\
\hline Tonkin et al., 1996 & 17 & Transfer \\
\hline Vekris et al., 2010 & 78 & Graft \\
\hline Venkatramani et al., 2008 & 15 & Transfer \\
\hline Waikakul et al., $1999^{79}$ & 96 & Transfer \\
\hline Waikakul et al., 199980 & 205 & Transfer \\
\hline Xu et al., 2002 & 15 & Transfer \\
\hline Xu et al., 2005 & 15 & Transfer \\
\hline Zyaei \& Saied, 2010 & 10 & Transfer \\
\hline
\end{tabular}

group in Table 2. There were no significant differences among the three groups with regard to patient age, sex ratio, or time between injury and surgical repair. Similarly, no significant pairwise differences existed. The duration of follow-up was significantly shorter in the nerve transfer group than in the graft or combined groups $(p<0.001$ in each case).

\section{Comparative Effectiveness}

Restoration of Elbow Flexion

As shown in Table 3, nerve grafting resulted in significantly better outcomes than either nerve transfer or combined procedures $(\mathrm{F}=4.71, \mathrm{p}=0.0097)$; pairwise comparisons demonstrated $\mathrm{p}$ values of 0.034 and 0.018 , respectively. Our experience with favorable outcomes following the Oberlin procedure, as opposed to non-Oberlin nerve transfers, prompted a secondary analysis. Separating partial ulnar nerve transfer from the other neurotization procedures revealed that the former was significantly 
TABLE 2. Summary of demographic and procedural factors for surgical groups treated for upper brachial plexus injuries

\begin{tabular}{lccccc}
\hline \multicolumn{1}{c}{ Factor } & Graft Mean \pm SD & Transfer Mean \pm SD & Combined Mean \pm SD & $F$ & $p$ Value \\
\hline Age (yrs) & $25.900 \pm 3.256$ & $26.418 \pm 3.357$ & $25.744 \pm 0.696$ & 0.205 & 0.815 \\
\hline Proportion of males & $0.917 \pm 0.031$ & $0.913 \pm 0.063$ & $0.855 \pm 0.047$ & 2.682 & 0.079 \\
\hline Injury-to-surgery period (mos) & $5.405 \pm 2.713$ & $5.078 \pm 1.332$ & $6.062 \pm 1.187$ & 0.954 & 0.391 \\
\hline Length of follow-up (mos) & $44.082 \pm 10.801$ & $29.928 \pm 10.973$ & $35.725 \pm 23.441$ & 6.377 & 0.003 \\
\hline
\end{tabular}

more successful $(\mathrm{F}=82.82, \mathrm{p}<0.001$; Table 3$)$, although the two did not differ from each other $(\mathrm{p}=0.289)$. Furthermore, when the Oberlin procedure was compared with nerve grafting or combined procedures, it was significantly more successful than either $(\mathrm{F}=53.14 ; \mathrm{p}<0.001)$.

\section{Restoration of Shoulder Abduction}

Nerve transfer was significantly more successful than the combined procedure $(\mathrm{p}=0.046)$, which in turn was significantly better than nerve grafting procedures $(\mathrm{F}=$ $5.53, \mathrm{p}=0.0044$; Table 3).

\section{Predictive Factors}

The mean patient age, sex distribution, delay to repair, length of follow-up, or year of publication had no significant correlation with outcome, as analyzed by meta-regression. This was true for analyses for both elbow flexion and shoulder abduction. In the nerve grafting group, graft length did not correlate with success rates of either elbow or shoulder surgery.

\section{Discussion}

Consensus on the most successful surgical treatment strategy for upper trunk brachial plexus injuries in adults is lacking, and in the absence of a randomized controlled trial to guide clinical decision making, we reviewed the literature to evaluate outcomes of three surgical approaches for the repair of postganglionic upper trunk brachial plexus injuries in adults, including nerve grafting, nerve transfer, and a combination of both techniques. Our

TABLE 3. Relative success of surgical procedures for upper brachial plexus injuries in adults

\begin{tabular}{llll}
\hline \multicolumn{1}{c}{ Procedure } & Mean \pm SD & F & p Value \\
\hline Restoring elbow flexion & & 4.71 & 0.0097 \\
\hline Graft & $0.692 \pm 0.241$ & & \\
\hline Transfer & $0.661 \pm 0.153$ & & \\
\hline Combined & $0.630 \pm 0.268$ & & \\
\hline Restoring elbow flexion & & 82.82 & $<0.001$ \\
\hline Oberlin & $0.825 \pm 0.122$ & & \\
\hline Intercostal & $0.658 \pm 0.167$ & & \\
\hline Other nerve transfer & $0.678 \pm 0.095$ & & \\
\hline Restoring shoulder abduction & & 5.53 & 0.0044 \\
\hline Graft & $0.560 \pm 0.260$ & & \\
\hline Transfer & $0.654 \pm 0.165$ & & \\
\hline Combined & $0.633 \pm 0.265$ & & \\
\hline
\end{tabular}

results indicated that the Oberlin procedure and nerve transfers were more successful approaches to the restoration of elbow flexion and shoulder abduction, respectively, than nerve grafting or combined techniques.

Our approach to pooling data from multiple published reports is similar to that used by Garg et al. ${ }^{21}$ as well as Yang and associates, ${ }^{83}$ although the model itself is somewhat different. Unlike those authors, we extended our analysis to include different nerve transfers and were able to show that partial ulnar transfer seemed to result in greater success in elbow flexion recovery than did graft repair. Yang et al. did not identify a reconstruction strategy that was superior for the recovery of shoulder abduction, whereas our data, like those of Garg et al., suggested that nerve transfer is superior to nerve grafting in the case of shoulder abduction recovery as well.

In upper trunk brachial plexus injuries in adults, according to our data, the Oberlin procedure and nerve transfers are more successful approaches to the restoration of elbow flexion and shoulder abduction, respectively, compared with nerve grafting or combined techniques. While the debate over nerve grafting versus nerve transfer has been ongoing among peripheral nerve surgeons over the last few decades, it is still unclear how one approach produces better outcomes than another. We hypothesize that the superiority of nerve transfers in promoting nerve regeneration is probably the result of a combination of factors, including a shorter distance required for nerve regeneration, single suture junction, use of a vascularized albeit injured nerve transfer recipient, and reduced fibrosis at the operative site as compared with that at the injury site. In the absence of a prospective, randomized clinical trial, resolving the debate over nerve transfer versus nerve graft is unlikely. However, data in the present study arm the clinician with valuable information that can be used to counsel patients when considering various surgical approaches.

A comparative effectiveness study is not the equivalent of a well-run and well-powered randomized controlled trial. At best, it can approximate the results of such a trial. As in any mathematical model, the many simplifications and assumptions may have influenced our conclusions, and the differences among groups are relatively small. However, this suggests that the rather large sample size needed would make a clinical trial impractical, especially in light of the impact of injury type on the repair technique and the lack of clinical equipoise among peripheral nerve experts. Our use of a dichotomous outcome, such as MRC scores above and below 3, has been reported to reduce the statistical power of clinical trials ${ }^{45}$ although this is not always the case..$^{28}$ 
This study has several additional limitations. Very few published case series reported outcomes stratified by injury mechanisms, and the indications for surgery were not uniform, thereby limiting our analysis. Thus, it is possible that the reported groups are not strictly comparable. Specifically, for the group undergoing combined procedures, it was not clear, based on the available literature, if both nerve grafts and transfers were performed to restore a common function. In addition, the reviewed literature lacked sufficient detail to determine which combinations of nerve grafts and transfers were most successful in restoring motor function. Moreover, in assessing outcomes for shoulder abduction, no distinction was made between specific targets for nerve reinnervation (that is, axillary versus suprascapular nerve), nor were adequate data available to separate success in restoring axillary versus suprascapular nerve function. In at least some cases, the findings at the time of exploration dictated surgical approach. If so, our comparison introduced a degree of selection bias, which might be avoided in a randomized controlled trial. We could not limit our analysis to cases in which there was clinical equipoise in surgical treatment, as very few publications separated outcomes of nerve transfers in patients with nerve root avulsions from those in patients with other brachial plexus lesions. In addition, variations in the intensity and duration of physical therapy can confound pooled results. Many secondary procedures, including osteotomies and tendon transfers, are available for these patients. Although they are widely used and affect function, we excluded them from this analysis since the goal of this study was to isolate the success of primary surgical approaches to brachial plexus injury.

The adult brachial plexus injury population is heterogeneous, and the clinician is responsible for considering several factors on an individual basis in developing an appropriate management plan for each patient. While our study provides a decision framework for the clinician to consider surgical treatment strategies, it should not serve as a substitute for the individualized clinical decision making required to manage these patients effectively. Furthermore, when considering brachial plexus reconstruction strategies, nerve transfers, without operative exploration of the supraclavicular brachial plexus, may limit the surgeon's appreciation of the unique pathology in each case.

\section{Conclusions}

In upper trunk brachial plexus injuries in adults, the Oberlin procedure and nerve transfers are more successful approaches to the restoration of elbow flexion and shoulder abduction, respectively, as compared with nerve grafting or combined techniques. A prospective, randomized controlled trial would be necessary to fully elucidate differences in outcomes among the various surgical approaches.

\section{References}

1. Addas BM, Midha R: Nerve transfers for severe nerve injury. Neurosurg Clin N Am 20:27-38, vi, 2009
2. Allieu Y, Chammas M, Picot MC: [Paralysis of the brachial plexus caused by supraclavicular injuries in the adult. Longterm comparative results of nerve grafts and transfers.] Rev Chir Orthop Repar Appar Mot 83:51-59, 1997 (Fr)

3. Belzberg AJ, Dorsi MJ, Storm PB, Moriarity JL: Surgical repair of brachial plexus injury: a multinational survey of experienced peripheral nerve surgeons. J Neurosurg 101:365-376, 2004

4. Berger A, Becker MH: Brachial plexus surgery: our concept of the last twelve years. Microsurgery 15:760-767, 1994

5. Bertelli JA, Ghizoni MF: Contralateral motor rootlets and ipsilateral nerve transfers in brachial plexus reconstruction. J Neurosurg 101:770-778, 2004

6. Bertelli JA, Ghizoni MF: Nerve root grafting and distal nerve transfers for C5-C6 brachial plexus injuries. J Hand Surg Am 35:769-775, 2010

7. Bertelli JA, Ghizoni MF: Reconstruction of C5 and C6 brachial plexus avulsion injury by multiple nerve transfers: spinal accessory to suprascapular, ulnar fascicles to biceps branch, and triceps long or lateral head branch to axillary nerve. J Hand Surg Am 29:131-139, 2004

8. Bertelli JA, Ghizoni MF: Reconstruction of complete palsies of the adult brachial plexus by root grafting using long grafts and nerve transfers to target nerves. J Hand Surg Am 35:1640-1646, 2010

9. Bhandari PS, Deb P: Fascicular selection for nerve transfers: the role of the nerve stimulator when restoring elbow flexion in brachial plexus injuries. J Hand Surg Am 36:2002-2009, 2011

10. Bhandari PS, Sadhotra LP, Bhargava P, Bath AS, Mukherjee MK, Bhatti T, et al: Surgical outcomes following nerve transfers in upper brachial plexus injuries. Indian J Plast Surg 42:150-160, 2009

11. Brown JM, Mackinnon SE: Nerve transfers in the forearm and hand. Hand Clin 24:319-340, v, 2008

12. Chuang DC, Lee GW, Hashem F, Wei FC: Restoration of shoulder abduction by nerve transfer in avulsed brachial plexus injury: evaluation of 99 patients with various nerve transfers. Plast Reconstr Surg 96:122-128, 1995

13. Chuang DC, Yeh MC, Wei FC: Intercostal nerve transfer of the musculocutaneous nerve in avulsed brachial plexus injuries: evaluation of 66 patients. J Hand Surg Am 17:822828,1992

14. Coulet B, Boretto JG, Lazerges C, Chammas M: A comparison of intercostal and partial ulnar nerve transfers in restoring elbow flexion following upper brachial plexus injury (C5C6 \pm C7). J Hand Surg Am 35:1297-1303, 2010

15. Doi K, Hattori Y, Ikeda K, Dhawan V: Significance of shoulder function in the reconstruction of prehension with double free-muscle transfer after complete paralysis of the brachial plexus. Plast Reconstr Surg 112:1596-1603, 2003

16. Dubuisson AS, Kline DG: Brachial plexus injury: a survey of 100 consecutive cases from a single service. Neurosurgery 51:673-683, 2002

17. Einarson TR: Pharmacoeconomic applications of metaanalysis for single groups using antifungal onychomycosis lacquers as an example. Clin Ther 19:559-569, 1997

18. El-Gammal TA, Fathi NA: Outcomes of surgical treatment of brachial plexus injuries using nerve grafting and nerve transfers. J Reconstr Microsurg 18:7-15, 2002

19. Ferraresi S, Garozzo D, Buffatti P: Reinnervation of the biceps in C5-7 brachial plexus avulsion injuries: results after distal bypass surgery. Neurosurg Focus 16(5):E6, 2004

20. Friedman AH, Nunley JA II, Goldner RD, Oakes WJ, Goldner JL, Urbaniak JR: Nerve transposition for the restoration of elbow flexion following brachial plexus avulsion injuries. J Neurosurg 72:59-64, 1990

21. Garg R, Merrell GA, Hillstrom HJ, Wolfe SW: Comparison of nerve transfers and nerve grafting for traumatic upper 
plexus palsy: a systematic review and analysis. J Bone Joint Surg Am 93:819-829, 2011

22. Goubier JN, Teboul F: Technique of the double nerve transfer to recover elbow flexion in C5, C6, or C5 to C7 brachial plexus palsy. Tech Hand Up Extrem Surg 11:15-17, 2007

23. Gu YD, Wu MM, Zhen YL, Zhao JA, Zhang GM, Chen DS, et al: Phrenic nerve transfer for treatment of root avulsion of the brachial plexus. Chin Med J (Engl) 103:267-270, 1990

24. Haninec P, Kaiser R: Axillary nerve repair by fascicle transfer from the ulnar or median nerve in upper brachial plexus palsy. Clinical article. J Neurosurg 117:610-614, 2012

25. Haninec P, Sámal F, Tomás R, Houstava L, Dubovwý P: Direct repair (nerve grafting), neurotization, and end-to-side neurorrhaphy in the treatment of brachial plexus injury. $\mathbf{J}$ Neurosurg 106:391-399, 2007

26. Hou Z, Xu Z: Nerve transfer for treatment of brachial plexus injury: comparison study between the transfer of partial median and ulnar nerves and that of phrenic and spinal accessary nerves. Chin J Traumatol 5:263-266, 2002

27. Htut M, Misra VP, Anand P, Birch R, Carlstedt T: Motor recovery and the breathing arm after brachial plexus surgical repairs, including re-implantation of avulsed spinal roots into the spinal cord. J Hand Surg Eur 32:170-178, 2007

28. Ilodigwe D, Murray GD, Kassell NF, Torner J, Kerr RS, Molyneux AJ, et al: Sliding dichotomy compared with fixed dichotomization of ordinal outcome scales in subarachnoid hemorrhage trials. Clinical article. J Neurosurg 118:3-12, 2013

29. Jivan S, Kumar N, Wiberg M, Kay S: The influence of presurgical delay on functional outcome after reconstruction of brachial plexus injuries. J Plast Reconstr Aesthet Surg 62:472-479, 2009

30. Kakinoki R, Ikeguchi R, Dunkan SF, Nakayama K, Matsumoto $\mathrm{T}$, Ohta $\mathrm{S}$, et al: Comparison between partial ulnar and intercostal nerve transfers for reconstructing elbow flexion in patients with upper brachial plexus injuries. J Brachial Plex Peripher Nerve Inj 5:4, 2010

31. Kandenwein JA, Kretschmer T, Engelhardt M, Richter HP, Antoniadis G: Surgical interventions for traumatic lesions of the brachial plexus: a retrospective study of 134 cases. J Neurosurg 103:614-621, 2005

32. Kim DH, Cho YJ, Tiel RL, Kline DG: Outcomes of surgery in 1019 brachial plexus lesions treated at Louisiana State University Health Sciences Center. J Neurosurg 98:1005-1016, 2003

33. King JT Jr, Berlin JA, Flamm ES: Morbidity and mortality from elective surgery for asymptomatic, unruptured, intracranial aneurysms: a meta-analysis. J Neurosurg 81:837-842, 1994

34. Kline DG: Civilian gunshot wounds to the brachial plexus. J Neurosurg 70:166-174, 1989

35. Leechavengvongs $\mathrm{S}$, Witoonchart $\mathrm{K}$, Uerpairojkit $\mathrm{C}$, Thuvasethakul P, Ketmalasiri W: Nerve transfer to biceps muscle using a part of the ulnar nerve in brachial plexus injury (upper arm type): a report of 32 cases. J Hand Surg Am 23:711-716, 1998

36. Leechavengvongs $\mathrm{S}$, Witoonchart $\mathrm{K}$, Uerpairojkit $\mathrm{C}$, Thuvasethakul P, Malungpaishrope K: Combined nerve transfers for C5 and C6 brachial plexus avulsion injury. J Hand Surg Am 31:183-189, 2006

37. Liverneaux PA, Diaz LC, Beaulieu JY, Durand S, Oberlin C: Preliminary results of double nerve transfer to restore elbow flexion in upper type brachial plexus palsies. Plast Reconstr Surg 117:915-919, 2006

38. Mackinnon SE, Colbert SH: Nerve transfers in the hand and upper extremity surgery. Tech Hand Up Extrem Surg 12:20-33, 2008

39. Malessy MJ, de Ruiter GC, de Boer KS, Thomeer RT: Evaluation of suprascapular nerve neurotization after nerve graft or transfer in the treatment of brachial plexus traction lesions. J Neurosurg 101:377-389, 2004

40. Malessy MJ, Hoffmann CF, Thomeer RT: Initial report on the limited value of hypoglossal nerve transfer to treat brachial plexus root avulsions. J Neurosurg 91:601-604, 1999

41. Malessy MJ, Thomeer RT: Evaluation of intercostal to musculocutaneous nerve transfer in reconstructive brachial plexus surgery. J Neurosurg 88:266-271, 1998

42. Medical Research Council: Aids to the Examination of the Peripheral Nervous System. Memorandum No. 45. London: Her Majesty's Stationary Office, 1976

43. Merrell GA, Barrie KA, Katz DL, Wolfe SW: Results of nerve transfer techniques for restoration of shoulder and elbow function in the context of a meta-analysis of the English literature. J Hand Surg Am 26:303-314, 2001

44. Moiyadi AV, Devi BI, Nair KP: Brachial plexus injuries: outcome following neurotization with intercostal nerve. $\mathbf{J}$ Neurosurg 107:308-313, 2007

45. Murray GD, Barer D, Choi S, Fernandes H, Gregson B, Lees $\mathrm{KR}$, et al: Design and analysis of phase III trials with ordered outcome scales: the concept of the sliding dichotomy. J Neurotrauma 22:511-517, 2005

46. Nagano A, Ochiai N, Okinaga S: Restoration of elbow flexion in root lesions of brachial plexus injuries. J Hand Surg Am 17:815-821, 1992

47. Nagano A, Tsuyama N, Ochiai N, Hara T, Takahashi M: Direct nerve crossing with the intercostal nerve to treat avulsion injuries of the brachial plexus. J Hand Surg Am 14:980985,1989

48. Nagano A, Yamamoto S, Mikami Y: Intercostal nerve transfer to restore upper extremity functions after brachial plexus injury. Ann Acad Med Singapore 24 (4 Suppl):42-45, 1995

49. Nath RK, Lyons AB, Bietz G: Physiological and clinical advantages of median nerve fascicle transfer to the musculocutaneous nerve following brachial plexus root avulsion injury. J Neurosurg 105:830-834, 2006

50. Ochiai N, Mikami Y, Yamamoto S, Nakagawa T, Nagano A: A new technique for mismatched nerve suture in direct intercostal nerve transfers. J Hand Surg Br 18:318-319, 1993

51. Ogino T, Naito T: Intercostal nerve crossing to restore elbow flexion and sensibility of the hand for a root avulsion type of brachial plexus injury. Microsurgery 16:571-577, 1995

52. Okinaga S, Nagano A: Can vascularization improve the surgical outcome of the intercostal nerve transfer for traumatic brachial plexus palsy? A clinical comparison of vascularized and non-vascularized methods. Microsurgery 19:176-180, 1999

53. Ray WZ, Pet MA, Yee A, Mackinnon SE: Double fascicular nerve transfer to the biceps and brachialis muscles after brachial plexus injury: clinical outcomes in a series of 29 cases. Clinical article. J Neurosurg 114:1520-1528, 2011

54. Ricardo M: Surgical treatment of brachial plexus injuries in adults. Int Orthop 29:351-354, 2005

55. Richardson PM: Recovery of biceps function after delayed repair for brachial plexus injury. J Trauma 42:791-792, 1997

56. Ruch DS, Friedman A, Nunley JA: The restoration of elbow flexion with intercostal nerve transfers. Clin Orthop Relat Res (314):95-103, 1995

57. Samadian M, Rezaee O, Haddadian K, Sharifi G, Abtahi H, Hamidian M, et al: Gunshot injuries to the brachial plexus during wartime. Br J Neurosurg 23:165-169, 2009

58. Samardzic M, Grujicic D, Antunovic V: Nerve transfer in brachial plexus traction injuries. J Neurosurg 76:191-197, 1992

59. Samardzić M, Grujicić D, Rasulić L, Milicić B: Restoration of upper arm function in traction injuries to the brachial plexus. Acta Neurochir (Wien) 144:327-335, 2002

60. Samii A, Carvalho GA, Samii M: Brachial plexus injury: fac- 
tors affecting functional outcome in spinal accessory nerve transfer for the restoration of elbow flexion. J Neurosurg 98:307-312, 2003

61. Samii M, Carvalho GA, Nikkhah G, Penkert G: Surgical reconstruction of the musculocutaneous nerve in traumatic brachial plexus injuries. J Neurosurg 87:881-886, 1997

62. Shin AY, Spinner RJ, Steinmann SP, Bishop AT: Adult traumatic brachial plexus injuries. J Am Acad Orthop Surg 13:382-396, 2005

63. Siqueira MG, Martins RS: Phrenic nerve transfer in the restoration of elbow flexion in brachial plexus avulsion injuries: how effective and safe is it? Neurosurgery 65 (4 Suppl):A125-A131, 2009

64. Socolovsky M, Di Masi G, Battaglia D: Use of long autologous nerve grafts in brachial plexus reconstruction: factors that affect the outcome. Acta Neurochir (Wien) 153:22312240, 2011

65. Socolovsky M, Martins RS, Di Masi G, Siqueira M: Upper brachial plexus injuries: grafts vs ulnar fascicle transfer to restore biceps muscle function. Neurosurgery 71 (2 Suppl Operative):ons227-ons232, 2012

66. Songcharoen P: Brachial plexus injury in Thailand: a report of 520 cases. Microsurgery 16:35-39, 1995

67. Songcharoen P, Mahaisavariya B, Chotigavanich C: Spinal accessory neurotization for restoration of elbow flexion in avulsion injuries of the brachial plexus. J Hand Surg Am 21:387-390, 1996

68. Songcharoen P, Wongtrakul S, Spinner RJ: Brachial plexus injuries in the adult. Nerve transfers: the Siriraj Hospital experience. Hand Clin 21:83-89, 2005

69. Sulaiman OA, Kim DD, Burkett C, Kline DG: Nerve transfer surgery for adult brachial plexus injury: a 10-year experience at Louisiana State University. Neurosurgery 65 (4 Suppl):A55-A62, 2009

70. Sungpet A, Suphachatwong C, Kawinwonggowith V: Restoration of shoulder abduction in brachial plexus injury with phrenic nerve transfer. Aust N Z J Surg 70:783-785, 2000

71. Sungpet A, Suphachatwong C, Kawinwonggowit V, Patradul A: Transfer of a single fascicle from the ulnar nerve to the biceps muscle after avulsions of upper roots of the brachial plexus. J Hand Surg Br 25:325-328, 2000

72. Suzuki K, Doi K, Hattori Y, Pagsaligan JM: Long-term results of spinal accessory nerve transfer to the suprascapular nerve in upper-type paralysis of brachial plexus injury. J Reconstr Microsurg 23:295-299, 2007

73. Teboul F, Kakkar R, Ameur N, Beaulieu JY, Oberlin C: Transfer of fascicles from the ulnar nerve to the nerve to the biceps in the treatment of upper brachial plexus palsy. J Bone Joint Surg Am 86-A:1485-1490, 2004

74. Terzis JK, Kostas I: Suprascapular nerve reconstruction in 118 cases of adult posttraumatic brachial plexus. Plast Reconstr Surg 117:613-629, 2006
75. Terzis JK, Vekris MD, Soucacos PN: Outcomes of brachial plexus reconstruction in 204 patients with devastating paralysis. Plast Reconstr Surg 104:1221-1240, 1999

76. Tonkin MA, Eckersley JR, Gschwind CR: The surgical treatment of brachial plexus injuries. Aust N Z J Surg 66:29-33, 1996

77. Vekris MD, Beris AE, Pafilas D, Lykissas MG, Xenakis TA, Soucacos PN: Shoulder reanimation in posttraumatic brachial plexus paralysis. Injury 41:312-318, 2010

78. Venkatramani H, Bhardwaj P, Faruquee SR, Sabapathy SR: Functional outcome of nerve transfer for restoration of shoulder and elbow function in upper brachial plexus injury. J Brachial Plex Peripher Nerve Inj 3:15, 2008

79. Waikakul S, Orapin S, Vanadurongwan V: Clinical results of contralateral $\mathrm{C} 7$ root neurotization to the median nerve in brachial plexus injuries with total root avulsions. J Hand Surg Br 24:556-560, 1999

80. Waikakul S, Wongtragul S, Vanadurongwan V: Restoration of elbow flexion in brachial plexus avulsion injury: comparing spinal accessory nerve transfer with intercostal nerve transfer. J Hand Surg Am 24:571-577, 1999

81. Xu WD, Gu YD, Xu JG, Tan LJ: Full-length phrenic nerve transfer by means of video-assisted thoracic surgery in treating brachial plexus avulsion injury. Plast Reconstr Surg 110:104-111, 2002

82. Xu WD, Xu JG, Gu YD: Comparative clinic study on vascularized and nonvascularized full-length phrenic nerve transfer. Microsurgery 25:16-20, 2005

83. Yang LJ, Chang KW, Chung KC: A systematic review of nerve transfer and nerve repair for the treatment of adult upper brachial plexus injury. Neurosurgery 71:417-429, 2012

84. Zyaei A, Saied A: Functional outcome of ulnar nerve fascicle transfer for restoration of elbow flexion in upper brachial plexus injury. Eur J Orthop Surg Traumatol 20:293-297, 2010

\section{Author Contributions}

Conception and design: Ali, Heuer, Stein, Zager. Acquisition of data: Faught, Kaneriya, Sheikh, Syed. Analysis and interpretation of data: Ali, Heuer, Stein, Zager. Drafting the article: Ali, Stein. Critically revising the article: all authors. Reviewed submitted version of manuscript: all authors. Approved the final version of the manuscript on behalf of all authors: Ali. Statistical analysis: Stein. Study supervision: Stein, Zager.

\section{Correspondence}

Zarina S. Ali, Department of Neurosurgery, University of Pennsylvania, 3400 Spruce St., 3rd Fl. Silverstein Pavilion, Philadelphia, PA 19104. email: zarinasali@gmail.com. 